\title{
An Introduction to Proposed Human Sexuality Counseling Competencies
}

\author{
Robert J. Zeglin ${ }^{1}$ • Dorothy Van Dam ${ }^{2}$ • Kenneth C. Hergenrather ${ }^{3}$
}

Published online: 23 October 2017

(C) Springer Science+Business Media, LLC 2017

\begin{abstract}
The presentation of human sexuality information within counselor education programs seems inconsistent, leaving counselors typically underprepared to handle the sexuality-related components of many clients' distress. Addressing this gap, the present article, using guidance from the American Association of Sexuality Educators, Counselors, and Therapists (AASECT), proposes 10 human sexuality counseling competency domains to aid counselors in working more effectively and comprehensively with clients. These domains are: Ethical/Professional Behavior, History and Systems, Anatomy/Physiology, Sexual Identity, Sexual Development, Intimacy and Interpersonal Relationships, Pleasure and Sexual Lifestyles, Sexual Functioning, Health/Medical Factors, and Sexual Exploitation. Clinical implications are discussed and include improved case conceptualization and developing counselor competence. Opportunities for future research are presented as they relate to counselor education and training.
\end{abstract}

Keywords Counseling competency · Human sexuality · Counselor training · Counseling supervision · Sex therapy

\section{Introduction}

Sexuality is an intimate and impactful part of an individual's identity (Hanzlik and Gaubatz 2012; Zeglin and Mitchell 2014), with sexual health being an important component of general wellbeing (Giami 2002; Higgins et al. 2006; McCabe et al. 2010; Southern and Cade 2011). It has been claimed that up to half of men and women in the U.S. experience clinical sexual

Robert J. Zeglin

r.zeglin@unf.edu

1 Department of Public Health, Brooks College of Health, The University of North Florida, 1 UNF Dr. Building 39, Room 4033, Jacksonville, FL 32224, USA

2 Counseling Center, The Catholic University of America, Washington, DC 20064, USA

3 Department of Counseling and Human Development, The George Washington University, Washington, DC 20037, USA 
dysfunction at some point in their lives (Heiman 2002; Simons and Carey 2001), and this can be assumed similarly to be the case in other societies around the world. Moreover, sexualityrelated concerns encompass more than dysfunction (Buehler 2013; Hertlein et al. 2012; McCabe et al. 2010; Southern and Cade 2011; Zeglin and Mitchell 2014), including as they do relationship issues, sexual identity struggles, intimacy concerns, and general life dissatisfaction. Such issues are not foreign to professional counselors, though they are often not discussed (Buehler 2013; Hanzlik and Gaubatz 2012; Juergens et al. 2009; Russell 2012; Southern and Cade 2011). In a study by Haboubi and Lincoln (2003), approximately $90 \%$ of health professionals agreed that addressing client sexuality was a critical part of health care, though $94 \%$ reported infrequently doing so.

Research (e.g., Haboubi and Lincoln 2003; Hanzlik and Gaubatz 2012; Harris and Hays 2008; Juergens et al. 2009; Russell 2012) has consistently shown that sexuality education/training and comfort with sexuality are associated with a professional's willingness to discuss sexual issues with clients. Historically, counselor education programs have rarely offered human sexuality coursework to students (Gray et al. 1989, 1996), with the Council for Accreditation of Counseling and Related Educational Programs (CACREP) not specifically requiring counseling education programs to include human sexuality coursework among its eight specified common core areas (CACREP 2009). Also, discomfort with sexuality-related topics has been identified as a common experience for clinicians (Hanzlik and Gaubatz 2012; Harris and Hays 2008). A recent study noted that half of the health professionals involved reported that embarrassment prevented discussion of sexuality (Haboubi and Lincoln 2003). The confluence of clinicians' lack of training and lack of comfort seems to potentiate a medicalized orientation towards sexual distress, commonly pushing clients to seek physiological explanations and treatments for concerns that often have psychological catalysts (Bradley and Fine 2009).

Before counselors can begin to gain competency in addressing sexuality-related distress, they must first establish comfort with the subject matter to be able to "facilitate frank, unembarrassed discussion of sex with individual clients and in group settings" (Kelly 1976, p. 355). This desensitization process would involve introducing counselors to a myriad of sexual behaviors, terms, attitudes, and lifestyles, thus challenging them to explore their own values regarding sexuality (Hertlein et al. 2012; Kelly 1976; Sitron and Dyson 2009; Stayton 1998).

Sexual Attitude Reassessment seminars (SARs) are one way by which to achieve this. Sitron and Dyson (2009) outlined the objectives of SARs including: to desensitize counselors from overreacting to sexual stimuli, to make counselors more tolerant of the spectrum of sexual behaviors, to have counselors consider varying points of view on controversial sexual topics, and to have counselors acknowledge that one's own personal sexual values are not sufficient for treating sexuality-related distress. Counselors attending a SAR will be exposed to media covering various sexuality-related topics (e.g., masturbation, heterosexual and homosexual intercourse, sexual identity terms, abortion, sexuality transmitted infections [STIs], sadism/masochism, fetishes) and engage in group discussions about their personal reactions. The goal of SARs is to support the development of a sexological worldview that includes sexual pluralism (Sitron and Dyson 2009, 2012; Stayton 1998), proposing that human sexuality exists on a continuum and that "normal" sexuality is ideological and socially constructed (Downing 2015; Zeglin and Mitchell 2014). Sensitivity to variations in human behavior is a hallmark of the counseling profession, and could also apply to human sexuality if counselors are provided the correct training (American Counseling Association [ACA] 2014; Haboubi and Lincoln 2003; Harris and Hays 2008; National Board for Certified Counselors [NBCC] 2012; Timm 2009). 
The American Association of Sexuality Educators, Counselors, and Therapists (AASECT) is the largest national body certifying clinicians as sex therapists in the United States, and requires that applicants attend a SAR as part of the certification. Not all counselors, however, seek to specialize in sex therapy. In fact, it could be argued that a "sex therapy" specialty may perpetuate the perception that sexuality is a taboo subject within the non-specialized care of other therapists (Binik and Meana 2009). Promoting the human sexuality competency of all counseling students would be critical in eliminating such a perception.

Short of obtaining the necessary post-licensure education, training, and experience for AASECT certification, counselors should have fundamental knowledge regarding the ubiquity of sexuality within their clients' lives and within their distress. Fyfe (1980) offered a five-part model for training counselors in human sexuality: 1) Sexual Awareness, 2) Understanding Sexual Value Systems, 3) Dealing with Sexuality in Counseling, 4) Sexual Dysfunctions and their Treatment, and 5) Sexual Enhancement. As such, Fyfe set the stage for the establishment of human sexuality counseling competencies. Unfortunately, however, little has been done to advance this cause.

The ACA Code of Ethics (ACA 2014) notes that counselors should "take steps to ensure the competence of their work" (p. 8). The NBCC Code of Ethics (NBCC 2012) also includes similar language, requiring that counselors "perform only those professional services for which they are qualified" (p. 3). Within the context of these stated professional expectations, the present article seeks to promote counselors' competency in effectively addressing sexualityrelated concerns within counseling, using guidance from AASECT to accomplish this goal.

AASECT (2015) presents 17 core knowledge areas (CKA) in which educators, counselors, and therapists who are or wish to become certified by AASECT must be proficient. The authors, one of whom is an AASECT certified sex therapist and a Board Certified Social Worker, reviewed these CKAs for common themes. Through this review, 10 common themes were identified and constitute the proposed sexuality counseling competency domains. These domains were reviewed and considered face valid by an independent reviewer who is a Licensed Professional Counselor. The proposed competencies and the corresponding CKAs are shown in Table 1.

The aim of the current manuscript was to propose likely domains of sexuality counseling competency rather than to directly strengthen said competencies, as such would only be attainable through balanced growth in one's knowledge, attitudes, and skills related to sexuality (Association for Multicultural Counseling and Development [AMCD] 1996). With this aim in mind, the following section will detail key research related to each of the proposed

Table 1 Proposed sexuality counseling competency domains and corresponding AASECT core knowledge areas

1. Ethical/Professional behavior

2. History and systems

3. Anatomy/Physiology

4. Sexual identity

5. Sexual development

6. Intimacy/Interpersonal relationships

7. Pleasure/Sexual lifestyles

8. Sexual functioning

9. Health/Medical factors

10. Sexual exploitation
A, O, Q
$\mathrm{N}, \mathrm{P}$
G
$\mathrm{D}$
B, C
E, $\mathrm{K}$
F, M
I
$\mathrm{H}, \mathrm{L}$
J

${ }^{\text {a }}$ Letters relate to AASECT (2015) 
sexuality counseling competency domains and offer examples of applicable skills (though not designed to be an exhaustive list). These domains represent the key content areas hypothesized to be critical to the development of sexuality counseling competency. This is the first known attempt to establish such a catalogue.

\section{Proposed Human Sexuality Counseling Competency Domains}

\section{Ethical/Professional Behavior}

Professional counselors must abide by the rules and regulations set forth by their state laws and their various codes of professional ethics. The ACA (2014) code of ethics outlines six principles of ethical practice and five core values, prioritizing as they do sensitivity to diversity and to clients' right to make their own life choices. Competent counselors should acknowledge clients' sexuality as one of many behavioral, cognitive, and affective experiences that comprise their lives. Counselors may, in their career, hear of a myriad of sexual expressions, and they should be mindful not to relegate personally unfamiliar sexual expressions or activities to the realm of disordered, deviant, or paraphilic conditions in their conceptualizations of clients. The ongoing evolution of the DSM reflects attempts to reduce such pathologizing by explicitly mentioning that non-typical sexual behavior is not inherently pathological (Downing 2015; Giami 2015), and counselors should, aligning with multicultural counseling competencies (see AMCD 1996), recognise sexuality as a cultural element. This can be reflected to clients through the use of judgment-neutral attitudes and jargon-free language.

Such principles are also important for counselors who will be involved in conducting or disseminating sexuality-related research, beyond what will be applicable in research in general. Because sexuality is a deeply personal experience, research participants' rights to privacy, confidentiality, and informed consent are paramount (Bentler and Abramson 1981; Samenow 2012). Because of the perceived shame surrounding some sexualities (see Downing 2015; Giami 2015), counselors may encounter considerable difficulties with participant recruitment (Sherry and Amidon 2010). This is a significant limitation of sexuality-related research and, as such, can be a considerable threat to external validity.

Bentler and Abramson (1981) highlighted the importance of theory-driven research hypotheses, as this can protect against the pathologizing of certain sexualities. Therefore, congruent with ACA (2014) and NBCC (2012) guidelines, counselors should not formulate research questions that seek to prove the maladaptation of certain sexual behaviors, but, rather, seek to understand such sexual expressions - and possibly their health outcomes - in a clearer, fuller, more holistic context. Finally, counselors should be mindful of the social impact of their published results. They should seek to present the results in an empirically valid manner that does not support any stigmatization of minority sexualities.

Applicable skills within this domain include the development of a) the disposition and language to broach and work through the discomfort of discussing sexuality topics, b) the communication skills to articulate a valid and culturally responsive theory-base for conducting sexuality-related research and constructing associated hypotheses, and c) the analytical and critical thinking skills to complete a thorough and unbiased literature review for treating or researching sexuality-related distress. By growing these and similar skills, counselors will be able to navigate competently the general ethical and professional considerations present when working with sexuality-related distress. Ethical practice should be the foundational aspiration of sexuality-competent counselors. 


\section{History and Systems}

Professional counselors should understand the evolution and current standing of approaches to sex therapy. Initially, sexual dysfunction was considered to be solely a manifestation of deeper psychological upset (see Freud 1949) and was frequently treated as such through intensive analytic psychotherapy (Leiblum 2006). Though some early theorists considered the role of behavioral interventions in treating sexual dysfunction, it was not until the work of Masters and Johnson $(1966,1970)$ that the modern iteration of sex therapy was born (Leiblum 2006; Wiederman 1998). This approach prioritized the behavioral and physiological components of sexuality. This, coupled with a psychological understanding of the human experience, produces a richer and more complete approach to addressing human sexual functioning (Kaplan 1974; Leiblum 2006). Competent counselors should be able to conceptualize the client's distress by integrating various theoretical frames (e.g., behavioral, psychodynamic, cognitive, biological). As such, counselors should, where necessary, refer clients for medical consultations to clarify the biological/physiological components of sexuality-related distress.

Also, counselors should have a working knowledge of models explaining human sexuality and the manner in which to address sexuality-related issues. The Circles of Sexuality (Dailey 1981) presents sexuality as having five constituent parts: intimacy, sensuality, sexual identity, sexual health and reproduction, and sexualization. Zeglin and Mitchell (2014) detail these components and propose that counselors be comfortably able to explore clients' experiences within each of these circles. Essentially, counselors should be aware that sexuality is multifaceted and extends far beyond the bedroom (see Kaplan 1974).

To address sexuality-related issues, counselors should be familiar with the PLISSIT model (Annon 1976). This model outlines a four-step approach to addressing sexuality-related distress: 1) Permission (given to clients to discuss and ask questions about sexuality), 2) Limited Information (i.e., provide clients with evidence-based information), 3) Specific Suggestions (for how to concretely address sexuality-related distress), and 4) Intensive Therapy (to uncover and treat psychological etiologies). Davis and Taylor (2006) detailed the PLISSIT model's role in counseling, prioritizing the important role that counselors play in permission giving. Trained as non-judgmental observers, counselors are able to not only directly give permission to clients (i.e., verbally) but can also indirectly create a safe enough space within the counseling relationship that permission becomes assumed. In the course of their work, counselors should consult sexual health journals including Archives of Sexual Behavior, American Journal of Sexuality Education, Journal of Sex Research, Journal of Marital and Family Therapy, and Psychology \& Sexuality.

Applicable skills within this domain include the development of a) the evaluation and assessment skills to appropriately integrate sexuality into a case formulation, b) the communication skills to foster an environment where clients feel safe to discuss and process sexuality-related topics, and c) the conceptualization skills to appropriately provide theory-based psychoeducation regarding sexuality. Developing these and related skills can aid counselors in competently infusing sexualityrelated themes into their case conceptualizations. Moreover, counselors can promote a space within the counseling room where sexuality is safe for clinical discussion.

\section{Anatomy/Physiology}

Sexuality-competent counselors should have a basic knowledge of anatomy. There are fundamental internal and external physiological structures in regard to sex and sexuality with which 
counselors should be familiar (Buehler 2013). External female structures include the mons pubis (the fatty area below the abdomen), vulva (the entire portion of the female genital anatomy that is visible; often incorrectly called the vagina), labia major and labia minora (large lips and small lips respectively), clitoris (highly sensitive structure designed solely for sexual pleasure; extends into the pelvis), introitus (the opening into the female reproductive tract), perineum (the area between the anus and the introitus), and areolas (dark area around the nipple).

Important internal female structures include the vagina (the canal that connects the cervix to the outside of the body), ovaries (from where eggs are released for fertilization), fallopian tubes (which transport eggs from ovaries to uterus), uterus (which supports the development of a fertilized egg; also called the womb), and cervix (the opening to the uterus). Important functional knowledge is that if no eggs become fertilized, the lining of the uterus is shed approximately every 28 days, during what is called a period - the menstrual cycle - with more than half of females being in their fertile window between days 12 and 13; this process stops once a female reaches menopause, usually around age 50 (Buehler 2013; Kaplan 1974; Wilcox et al. 2000).

Male external structures with which to be familiar include the shaft (the main part of the penis), the glans (the highly sensitive head of the penis), the frenulum (the area on the underside of the penis that connects the glans to the shaft), the scrotum (the sac containing the testicles), and the perineum (the area between the anus and the scrotum). The penis has approximately half of the nerve endings as in the female clitoris, roughly 4000 compared to 8000 (Angier 1999).

Important male internal structures include the corpus cavernosum and corpus spongiosum (three small tubes that run the length of the shaft and fill with blood causing an erection), testicles (produce sperm), epididymis and vans deferens (tubes that carry sperm from the testicles to the urethra; the latter tube is severed in a vasectomy to prevent pregnancy), seminal vesicles (produce most of the fluid produced during ejaculation; often called "cum"), prostate gland (produces additional fluid during ejaculation), and Cowper's gland (produces a small amount of fluid before ejaculation to lubricate the urethra; this is sometimes called "pre cum").

Counselors who may be unfamiliar with any of the above structures and functions are encouraged to research them on medically reputable sites, including the National Library of Medicine at http://www.nlm.nih.gov/medlineplus/. They should also be familiar with colloquial terms, as this may be the language most known and used by clients.

Applicable skills within this domain include the development of a) the disposition and communication skills to adequately describe the role and function of various anatomical structures and b) the assessment and evaluation skills to properly ascertain pertinent information related to physiological sexual functioning. Through developing these and similar skills, counselors will be better able to competently integrate physiological information into their discussions and differential diagnoses. Additionally, counselors will be able to provide valid information and feedback to clients, thus empowering them with knowledge pertaining to their own bodies.

\section{Sexual Identity}

An individual's sexual identity is a confluence of several distinct constructs and experiences, can vary over time, and is always deeply personal (Downing 2015; Zeglin and Mitchell 2014). Shively and de Cecco (1993) presented detailed explanations of the four components of sexual identity: 1) Biological sex, 2) Gender identity, 3) Gender expression, and 4) Sexual orientation. These components are independent from one another, and do not directly influence each other. That is to say, for example, that biological sex does not determine sexual orientation, but can 
nonetheless inform its expression and/or a person's experience thereof. Sexuality-competent counselors should be familiar with the fundamental components of sexual identity, explore their own biases toward any of these components, and understand the cooperative rather than deterministic relationship between them.

Biological sex is in reference to the physiological make-up of the individual, typically with reference to the genitalia. Although this is commonly presented in dichotomy form as penises or vulvas (men and women respectively), individuals can also be intersex (i.e., having ambiguous genitalia; Meyer-Bahlburg 2005). Gender identity refers to the internal feelings of gender with which an individual identifies. Again, this is often dichotomized into male or female, but also includes a number of other gender identities including gender queer, gender ambiguous, transgender, and more. Gender expression is the outward enactment of gendered behavior, typically referred to (again, in dichotomy form) as masculinity and femininity. Gender can be expressed through dress, hobbies, mannerisms, and other behaviors. Sexual orientation describes the romantic attractions of an individual, which can include, among others, straight/heterosexual, gay/homosexual, bisexual, pansexual, and asexual.

It is important for counselors to note that these components of identity do not determine each other, and each can be conceptualized along a continuum (Downing 2015; Shively and de Cecco 1993; Zeglin and Mitchell 2014). A popular Tedx Talk further describing some of these identities is available at https://www.youtube.com/watch?v=NRcPXtqdKjE.

Applicable skills within this domain include the development of a) the disposition and communication skills to sensitively broach the topic of sexual identity, b) the conceptualization skills to provide thorough psychoeducation regarding the complexity of sexual identity, and c) the advocacy skills to appropriately promote social justice for clients from the sexual and gender minority population. By developing these and related skills, counselors can competently engage clients in a bidirectional clinical dialogue about sexual identity and provide valid information to populations who may struggle accessing such (e.g., children and teens). Moreover, counselors will also be able to capably support the demand for equal rights for all client populations.

\section{Sexual Development}

Sexuality-competent counselors should be able to conceptualize a client's sexual concerns within a developmental context, as one's sexuality can and does evolve over the lifetime (Buehler 2013; Giami 2002; Kaplan 1974; Zeglin and Mitchell 2014). DeLamater and Friedrich (2002) presented four stages of sexuality development, each having biological and psychosocial influences: 1) Childhood sexuality, 2) Adolescent sexuality, 3) Adult sexuality, and 4) Older adult sexuality. A full presentation of these stages is outside the scope of the present article; readers should consult Buehler (2013) and DeLamater and Friedrich (2002) for detailed explanations of the stages.

Biologically, there are certain physiological realities that come with touching certain parts of the body. These realities are discovered early in life, with children as young as two displaying masturbatory behaviors. They may, therefore, become curious about the bodies and experiences of others (e.g., playing doctor; Buehler 2013; Martinson 1994; Masters et al. 1995). As children enter adolescence and experience puberty, hormones cause physical changes as well as increase sexual behavior, including dating, exploration of sexual identity, and sexual intercourse.

Nearly half of U.S. high school students report having had sexual intercourse (Advocates for Youth [AFY] 2007; Buehler 2013; Centers for Disease Control and Prevention [CDC] 
2014; DeLamater and Friedrich 2002). The biological ability to produce offspring is established during adolescence and continues into adulthood and, save for medical influences, this ability lasts to older age. During these later years, women and men can experience menopause and andropause respectively. Women stop releasing eggs for fertilization and vaginal lubrication may be more difficult. Men experience a decrease in testosterone production, erections become more difficult to obtain, and the refectory period will lengthen (AFY 2007; Buehler 2013; DeLamater and Friedrich 2002).

Developmental psychosocial forces are also present. For young children, the discovery of physiologic pleasure runs up against societal restrictions placed on sexualized behaviors, with such restrictions being helpful (e.g., do not touch others' private parts) or unhelpful (e.g., touching your own private parts is shameful). Family is often the only sociocultural informant at this stage and plays a large role in shaping sexuality. This includes modeling displays of affection through hugging, kissing, and cuddling (Buehler 2013; Martinson 1994).

Adolescents are also curious about their sexuality in the social sphere, learning to establish and maintain relationships, including intimate ones. The feedback received from family, friends, and the community influences what relationships they perceive as being acceptable (AFY 2007; Buehler 2013; Pfaus et al. 2001). In adulthood, sexual identity may continue to be explored with new independence, although individuals who do not feel that they meet the social expectations of their sexual identity can experience gender role strain (Buehler 2013; Pleck 1995). Social pressures surrounding marriage and children are present throughout adulthood, and for older adults, sexuality may evolve into being companionship-based rather than intercourse-based. This is not to say that older adults do not have and enjoy sex, as they do, but the frequency and intensity may differ greatly from younger years (Buehler 2013; Price 2011; Pfaus et al. 2001; Van Sevenant 2005; Weeks 2002).

Applicable counseling skills within this domain include the development of a) the conceptualization skills to appropriately place client distress within a sexual developmental model and b) the communication skills to adequately describe the sexual maturation process. By growing these and similar skills, counselors can, again, be a competent source of valid information related to sexual development, helping to reduce clients' and guardians' possible stigma around sexualized behavior. With such skills, counselors will also be able to create more thorough case formulations.

\section{Intimacy and Interpersonal Relationships}

Sexuality-competent counselors should be aware of how clients' sexuality may be typified through and/or constructed by their interpersonal relationships. Van Sevenant (2005) posited that intimacy, particularly in sexual relationships, is a process of baring what lies within oneself to another. This interpersonal intimacy is a connection between people that fosters empathy and protects against exploitation (Schur 1988). Such intimacy can be emotional, sexual, or spiritual and is correlated with cooperative interpersonal relationships. Furthermore, counselors should be mindful of how childhood family dynamics can influence later life interpersonal intimacy (Bell and Bell 2005; Connelly and Ones 2010; Stoyanova 2011; Zeglin and Mitchell 2014).

Congruent with this conceptualization of intimacy and interpersonal relationships, it is important for counselors to assess the attachment styles of clients (Buehler 2013). Ainsworth et al. (1978) presented three types of attachment: 1) anxious/ambivalent, 2) avoidant, and 3) secure. These attachment styles have been found to be significantly associated with sexuality, including self-rated attractiveness, number of sexual partners, age of first intercourse, desire for 
alternative sexual partners, condom usage, sexual dysfunction, and infidelity (Bogaert and Sadava 2002; Lydon and Karremans 2015; Stefanou and McCabe 2012). Because of the clear association between attachment and sexuality, counselors should employ informal (Daniel 2006) and/or formal measures (Ravitz et al. 2010) of attachment in order to better understand or clarify their clients' experience of interpersonal intimacy and, therefore, of sexuality (Buehler 2013; Zeglin and Mitchell 2014).

Applicable skills within this domain include the development of a) the communication skills to effectively model and foster a healthy interpersonal relationship, b) the assessment and evaluation skills to adequately and effectively determine the client's attachment style, and c) the conceptualization skills to appropriately include the client's interpersonal style in case formulations. Developing these and related skills can support a counselor in competently navigating the therapeutic relationship, aiding both the client and the counselor in processing the client's experience of close relationships (see Teyber and McClure 2011). This, of course, is already a staple of counseling in general and has clear applicability to sexuality-related distress as well.

\section{Pleasure and Sexual Lifestyles}

Sexuality-competent counselors should maintain an unbiased stance towards the variety of sexual lifestyles possibly expressed by their clients, maintaining a pleasure-inclusive perspective of sexual behavior. This means appreciating that clients will potentially have unique and personal ways of deriving pleasure from sexual activity, some of which may be unfamiliar to the counselor (Buehler 2013; Kolmes et al. 2006; Lewis 2012). Various sexual lifestyles and notes about pleasure are described below, but counselors wishing to gain additional information should consult Kaplan (1974) and Buehler (2013).

Sexual lifestyles can include, among many others, monogamy (i.e., strictly one partner), polyamory (i.e., two or more partners in a committed relationship), swinging (i.e., sharing sexual partners), kink (i.e., slang term to describe sexual activity that is not 'vanilla' or traditional; this can include using toys, role play, fetishes, power play), and BDSM (i.e., bondage, discipline, dominance, submission, sadism, masochism). Any of these lifestyles may be deeply held identities, allowing counselors to explore the lifestyle's role in the client's distress, as well as possible sources of strength. For example, a monogamous couple may find tremendous strength and support in knowing that their partner knows them more intimately than anybody else, a source of support that can be leveraged to aid the counseling work. Simultaneously, a kink couple may experience a deep intimate trust when practicing sexual bondage, with such trust open to being explored and employed outside of the bedroom for therapeutic gain.

It would be impossible for the present article to review all pleasure enhancing practices. However, it is important for counselor to know that sexual pleasure can begin well before the initiation of sexual activity (Kaplan 1974; Van Sevenant 2005). This involves a couple collaboratively building the sexual tension between them throughout the day(s) leading up to sexual intercourse (Kaplan 1974). Additionally, once sexual activity begins, the role of foreplay should not be underestimated (Buehler 2013); sufficient time should be placed on stimulating one's partner's full body. This can include more docile activities (e.g., foot rub; eye-gazing) to more direct practices (e.g., sucking on nipples). For some, foreplay itself can be the goal of a sexual encounter (Buehler 2013; Kaplan 1974; Van Sevenant 2005).

Regarding sexual intercourse, there are a myriad of positions and techniques for partners to explore; each may be more or less pleasurable for the people involved, with no two people being alike in this regard. One common theme, however, pertaining to women's sexual response, is the 
primacy of clitoral stimulation to enhance pleasure (Buehler 2013; Kaplan 1974), with Angier (1999) noting that insertion of a penis or other object into the vagina is not necessary to stimulate most of the available nerve endings. To aid clients in enhancing pleasure, counselors can recommend helpful resources including books (e.g., Guide to Getting It On; The Joy of Sex) and podcasts (e.g., Lesbian Love Talk; Sex Nerd Sandra; Sex with Emily; The Gay Love Coach). It is important to note that, in all circumstances, communication and consent are paramount to promote pleasure, with communication being correlated with sexual satisfaction (Fuentes and Iglesias 2014; Timm and Keiley 2011). Counselors should work with clients to increase sexual communication (e.g., communicating needs, desires, interests), recognizing that sexual activity performed without the consent of all involved is exploitative and illegal, and should not be promoted by counselors (see later for matters to do with Sexual Exploitation).

Applicable skills within this domain include the development of a) the analytical and application skills to provide clinically relevant resources, b) the conceptualization skills to provide valid information regarding the continuum of sexual behavior and pleasure, and c) the disposition and communication skills to foster an environment for clients to feel safe enough to discuss and process their sexual behaviors and pleasure. By growing these and other skills, counselors can more competently foster therapeutic rapport with clients presenting with sexuality-related distress. Subsequently, the ability for the counselor to provide meaningful feedback and resources is also strengthened.

\section{Sexual Functioning}

Sexuality-competent counselors should be familiar with the human sexual response cycle (Masters and Johnson 1966). This model presents four stages of human sexual functioning during a sexual encounter: 1) Excitement, 2) Plateau, 3) Orgasm, and 4) Refractory. During the excitement (or arousal) stage, the sympathetic nervous system becomes activated, increasing heart rate, respiration rate, and blood pressure. Skin may become flush, individuals may sweat, and muscles may begin to contract involuntarily. For males, the penis become partially erect and the testicles are pulled closer to the body, and for females, the labia and clitoris may darken in color and begin to swell, the vagina begins self-lubrication, and the uterus expands. In the plateau stage, most of the events described above continue; the penis reaches full tumescence and may release small amounts of preejaculatory fluid, while the vagina increases lubrication. Sexual pleasure is heightened in this stage, as various erogenous zones may become particularly sensitive. The orgasmic stage is the height of sexual pleasure and is often typified by involuntary muscle contractions and intense waves of euphoria, with, as part of this, men ejaculating and women experiencing rapidly increased vaginal lubrication (possibly resulting in a sudden discharge of fluid).

Finally, the refractory stage follows orgasm, and the body's systems largely return to normal as the parasympathetic nervous system activates. The penis returns to its flaccid state, possibly after a period of semi-tumescence, and the clitoris may become extremely sensitive (and possibly cause some discomfort if stimulated) directly after orgasm. It is difficult for men to achieve orgasm during the refractory stage. Women, however, may experience such a short refractory stage that it appears nonexistent, often allowing for multiple orgasms (Archer and Lloyd 2002; Buehler 2013; Masters and Johnson 1966). Deviations from this cycle that cause distress might be considered sexual dysfunction (American Psychiatric Association [APA] 2013). This traditionally linear conceptualization of the sexual response cycle and its use as the sole guidepost against which to diagnose sexual dysfunction is not without challenge however (Downing 2015; Giami 2015). 
Applicable counseling skills within this domain include the development of a) the assessment and evaluation skills to appropriately and fully identify sexual dysfunctions and b) the disposition and communication skills to create an environment in which the client feels safe enough to discuss and process sexual functioning. Developing these and related skills can support a counselor in competently identifying sexual dysfunction. This, then, allows a more fully developed case formulation and treatment recommendations.

\section{Health/Medical Factors}

Sexuality-competent counselors should be aware of the broad categories describing the significant health and medical factors associated with human sexuality, although it would be difficult for counselors to be familiar with them all. Such factors can be classified as: 1) Medical Conditions and Treatment Side Effects, and 2) STIs (APA 2013; Buehler 2013). Counselors should be attuned to clients who report any of these, as they may be influencing the client's experience of sexuality (Buehler 2013; Kaplan 1974; Heiman 2002; McCabe et al. 2010).

The number of medical conditions that may present with comorbid sexual dysfunction is far too numerous for the present article to cover. For example, searching Google Scholar for "diabetes and sexual dysfunction" produces around 148,000 results. Essentially, any medical condition that effects the nervous, cardiovascular, endocrine, gastrointestinal, or musculoskeletal bodily systems can disrupt sexual functioning, including experiencing pleasure (APA 2013; Buehler 2013; Kaplan 1974; McCabe et al. 2010). It is also important not to desexualize individuals with disabilities, as the sexuality of clients from this population should also be appropriately considered (McCabe and Taleporos 2003). Additionally, the treatment for many health conditions, including mental illness, can have sexuality-related side-effects. For example, the class of antidepressants called selectiveserotonin reuptake inhibitors (SSRIs) has been associated with sexual dysfunction (Balon 2006; Buehler 2013). Counselors should judiciously inquire about sexual effects as the result of reported medical conditions and/or of their treatment.

Counselors should also be aware of the threat of STIs resulting from risky sexual activity. There are approximately 20 million new STIs cases in the U.S. annually (CDC 2016). The most common STIs include chlamydia, gonorrhea, syphilis, herpes, human papillomavirus (HPV), hepatitis B, HIV, and trichomoniasis. Though some STIs are curable (e.g., gonorrhea), others are not (e.g., HIV). Moreover, though some STIs can present with few to no symptoms, they can cause significant health issues later in life (e.g., HPV's link to cervical cancer; CDC 2013, 2015). The CDC (2015) offers helpful resources regarding STIs. Counselors should judiciously assess for sexual risk and provide accurate non-judgmental information regarding preventative measures, including male and female condoms, vaccines, dental dams, exploring less risky behavior, and abstinence (Buehler 2013; CDC 2013, 2015, 2016; Kaplan 1974; Kooyman 2008; Zeglin 2015).

Applicable counseling skills within this domain include the development of a) the assessment skills to appropriately and fully determine the presence of health factors, b) the conceptualization skills to adequately incorporate biological factors into case formulations, c) the communication skills to provide meaningful and accurate psychoeducation related to sexual health, and d) the evaluation skills to appropriately determine if and when a medical consult is indicated. Growing these and other related skills can, perhaps more than in any other domain, support the role of counselors as a competent member of an interdisciplinary healthcare team. Not only can the counselor directly influence a client's sexuality-related health through more developed case formulations, but also indirectly through professional collaboration. 


\section{Sexual Exploitation}

Sexuality-competent counselors should be aware of the salient role of power in sexual relationships, noting when such power may be employed to control or manipulate. The World Health Organization (2006) defines sexual health as "having pleasurable and safe sexual experiences, free of coercion, discrimination and violence" (p. 5). Such exploitation might be expressed in seemingly benign forms (e.g., withholding sex as punishment), but, at the core, are a means of manipulating the power dynamic within a relationship (AFY 2007; Brezsnyak and Whisman 2004). Exploitation can also manifest more overtly, as in the case of rape (including date rape and spousal rape), child sexual abuse, sex trafficking, and forced prostitution (Constable 2009; Zeglin 2014). Counselors should judiciously inquire about and take note of possible exploitation or coercion in clients' sexual experiences.

Applicable counseling skills within this domain include the development of a) the disposition and communication skills to judiciously and tactfully broach and process the topic of sexual exploitation and b) the assessment skills to adequately determine the possible presence of sexual exploitation. Growing these and similar skills allows a counselor to competently provide a truly safe space for personal exploration. Some of the foundational skills for assessing sexual exploitation are already part of counselor identity and repertoire in assessing for risk among clients (ACA 2014).

\section{The Role of Culture}

Sexuality is expressed, of course, within the context of one's culture (Dailey 1981; Zeglin and Mitchell 2014). Counselors should therefore be mindful and attentive to the influence of culture on sexuality, including sexual norms, language, behavior, and taboos. Not only will counselors inevitably work with clients with varying backgrounds and identities, but also, as an international profession, counselors around the world might find themselves positioned within a culture that views sexuality fundamentally differently than what is presented above.

The societal discussion of sexuality-related topics within a geographic region can have an effect on how clients may present to counseling with sexuality-related distress. In the Netherlands, for example, sex education is now starting in kindergarten as part of the country's plan for comprehensive sex education (De Melker 2015). Such education can influence how children, teens, and adults navigate their sexuality, including improving sexual health (Weaver et al. 2005). Advocates for Youth (2011) noted that, despite relatively similar ages of first intercourse, the rate of teen births in the United States was approximately $200 \%$ higher than in Canada. Sex education in Canada also begins early, with children as young as five being introduced to the names of body parts (Young 2015). This education in Canada also covers topics like sexting, gender identity, and sexual orientation as children age. Sex education is just one factor that may influence a counselor's contextual placement within their client's sexuality-related distress. For example, the degree to which a country or region is accepting of sex work, same-sex relationships, transgender people, and polyamory can inform a counselor's work with sexuality-related distress. Counselors around the world should consider the social norms surrounding sex and sexuality-related topics within their country and reflect on a) in what ways, if any, is their level of competency in any of the above domains affected and b) in what ways can they improve their competency in said domains while remaining culturally congruent? 


\section{Implications for Counseling Practice, Education, and Research}

As discussed above, counseling competence can be conceptualized as gaining sufficient knowledge, attitudes, skills related to a particular topic (AMCD 1996). In general, exposure to the information presented above only supports the growth of their sexuality-related knowledge and attitudes (Fyfe 1980; Harris and Hays 2008; Kelly 1976). This can certainly begin the process of growing competence. However, counselors who are interested in further building their human sexuality counseling competency are encouraged to attend a SAR or similar, to begin distilling and synthesizing their sexuality knowledge and attitudes. Available SARs can be found at http://www.aasect.org/continuing-education. Additionally, counselors can begin to strengthen their sexuality-related skills by continuing to research the many models presented above. For example, the PLISSIT model can help counselors develop rapport and provide helpful feedback and information to clients (see Timm 2009). In addition, counselors can continue to gain comfort with their clients' sexuality, possibly as easily as judiciously encouraging clients to explore their Circles of Sexuality (see Zeglin and Mitchell 2014). This approach could aid counselors in more thoughtfully and accurately assessing the sexualityrelated components of their clients' distress, leading to informed and appropriate referrals, with the present article providing important information and language to use in this endeavor. Only by addressing all three components of competency, particularly though experiential learning (e.g., practicums, clinical supervision from a certified sex therapist), can a counselor ethically and confidently claim competence with sexuality-related issues.

Continued research is still necessary to better understand: a) the role of human sexuality in the training of counselors, and b) the most efficient way to provide essential human sexuality training to counselors-in-training (CIT). To answer the first question, future research should consider identifying to what extent CIT have the proper knowledge, skills, and attitudes to identify and treat sexuality-related concerns (Russell 2012). Knowledge can include assessing CIT level of concrete knowledge regarding human sexuality, while skills can include assessing CITs' ability to identify sexuality-related material, accurately integrate it into a case formulation, appropriately address it in the room, and to incorporate it into treatment planning. Attitudes can include assessing CITs' level of self-awareness and self-reflection, with this being able to include their level of comfort with sexual material. The present article, if provided to CIT, can in itself directly aid in their developing improved knowledge and attitudes.

The second major research focus should begin to develop a human-sexuality training curriculum, the framework for which could be the proposed counseling competency domains. For example, considering a 15-week human sexuality course, if an instructor spends one week on each domain to develop knowledge and attitudes, this would leave five weeks for students to practice and develop skills, including the ones described above. This skills practice could include role plays, group projects, and/or demonstrations. In any case, human sexuality is diverse, dynamic, and unique to each person, so facilitating large group discussion of the kind of material presented here could challenge existing schemas and strengthen clinical acumen. Future research could identify the best way to achieve this, either within a dedicated human sexuality course or through sensible incorporation of the material within other courses.

Additionally, counselor educators - especially those tasked with teaching human sexuality courses - could consider including qualities of SARs in their instruction in order to facilitate a desensitization process (Rosser et al. 1995; Sitron and Dyson 2009, 2012; Stayton 1998). Moreover, because of sexuality's demonstrated ubiquity, it seems that it would be helpful for counselor education programs to include human sexuality material in other courses by 
thoughtfully incorporating the proposed competencies into the curriculum where appropriate (e.g., Health/Medical Factors in an assessment course; Sexuality Development in a human development course).

\section{Compliance with Ethical Standards}

Conflict of Interest The authors declare that they have no conflict of interest.

\section{References}

Advocates for Youth. (2007). Life planning education: A comprehensive sex education curriculum. Washington, DC: Author.

Advocates for Youth (2011). The sexual health of teens in Canada, United Kingdom, and the United States. Retrieved from http:/www.advocatesforyouth.org/publications/publications-a-z/1894-the-sexual-health-ofteens-in-canada-united-kingdom-and-the-united-states. Accessed 8 May 2017.

Ainsworth, M. D. S., Blehar, M. C., Waters, E., \& Wall, S. (1978). Patterns of attachment: A psychological study of the strange situation. New York: Lawrence Erlbaum.

American Association of Sexuality Educators, Counselors, and Therapists. (2015). Core knowledge. Core Knowledge Areas. Retrieved from http:/www.aasect.org/certification/core-knowledge-areas. Accessed 19 Mar 2015.

American Counseling Association. (2014). Code of ethics. Alexandria: Author.

American Psychiatric Association. (2013). Diagnostic and statistical manual of mental disorders (DSM-5®). Arlington: Author.

Angier, N. (1999). Woman: An intimate geography. New York: Houghton Mifflin Harcourt.

Annon, J. S. (1976). The PLISSIT model: A proposed conceptual scheme for the behavioral treatment of sexual problems. Journal of Sex Education and Therapy, 2(1), 1-15.

Archer, J., \& Lloyd, B. (2002). Sex and gender. New York: Cambridge University Press.

Association for Multicultural Counseling and Development. (1996). AMCD multicultural counseling competencies. Alexandria: Author.

Balon, R. (2006). SSRI-associated sexual dysfunction. American Journal of Psychiatry, 163(9), 1504-1509.

Bell, L. G., \& Bell, D. C. (2005). Family dynamics in adolescence affect midlife well-being. Journal of Family Psychology, 19(2), 198-211.

Bentler, P. M., \& Abramson, P. R. (1981). The science of sex research: Some methodological considerations. Archives of Sexual Behavior, 10(3), 225-251.

Binik, Y. M., \& Meana, M. (2009). The future of sex therapy: Specialization or marginalization? Archives of Sexual Behavior, 38(6), 1016-1027.

Bogaert, A. F., \& Sadava, S. (2002). Adult attachment and sexual behavior. Personal Relationships, 9(2), $191-204$.

Bradley, P. D., \& Fine, R. W. (2009). The medicalization of sex therapy: A call to action for therapists. Journal of Systemic Therapies, 28(2), 75-88.

Brezsnyak, M., \& Whisman, M. A. (2004). Sexual desire and relationship functioning: The effects of marital satisfaction and power. Journal of Sex \& Marital Therapy, 30(3), 199-217.

Buehler, S. (2013). What every mental health professional needs to know about sex. New York: Springer Publishing Company.

Centers for Disease Control and Prevention. (2013). Incidence, prevalence, and cost of sexually transmitted infections in the United States. CDC Fact Sheet. Retrieved from http://www.cdc.gov/std/stats/sti-estimatesfact-sheet-feb-2013.pdf. Accessed 18 Aug 2015.

Centers for Disease Control and Prevention. (2014). Youth risk behavior survey. Morbidity and Mortality Weekly Report, 63(4), 1-168.

Centers for Disease Control and Prevention. (2015). Diseases and related conditions. Sexually transmitted diseases (STDs). Retrieved from http://www.cdc.gov/std/. Accessed $30 \mathrm{July} 2015$.

Centers for Disease Control and Prevention. (2016). Reported STDs in the United States. CDC Fact Sheet. Retrieved from https://www.cdc.gov/nchhstp/newsroom/docs/factsheets/std-trends-508.pdf. Accessed 3 May 2017.

Connelly, B. S., \& Ones, D. S. (2010). An other perspective on personality: Meta-analytic integration of observers' accuracy and predictive validity. Psychological Bulletin, 136(6), 1092-1122. 
Constable, N. (2009). The commodification of intimacy: Marriage, sex, and reproductive labor. Annual Review of Anthropology, 38, 49-64.

Council for Accreditation of Counseling and Related Educational Programs. (2009). CACREP standards. Retrieved from http://www.cacrep.org/wp-content/uploads/2013/12/2009-Standards.pdf. Accessed19 April 2015.

Dailey, D. M. (1981). Sexual expression and aging. In F. J. Berghorn, D. E. Schafer, \& Associates (Eds.), The dynamics of aging: Original essays on the processes and experiences of growing old (pp. 311-330). Boulder: Westview Press.

Daniel, S. I. (2006). Adult attachment patterns and individual psychotherapy: A review. Clinical Psychology Review, 26(8), 968-984.

Davis, S., \& Taylor, B. (2006). From PLISSIT to ex-PLISSIT. In S. Davis (Ed.), Rehabilitation: The use of theories and models in practice (pp. 101-129). Philadelphia: Elsevier.

De Melker, S. (2015, May 27). The case for starting sex education in kindergarten. PBS Newshour Retrieved from http://www.pbs.org/newshour/updates/spring-fever/. Accessed 8 May 2017.

DeLamater, J., \& Friedrich, W. N. (2002). Human sexual development. Journal of Sex Research, 39(1), 10-14.

Downing, L. (2015). Heteronormativity and repronormativity in sexological "perversion theory" and the DSM5's "paraphilic disorder" diagnoses. Archives of Sexual Behavior. On-line First from http://link.springer. com/article/10.1007/s10508-015-0536-y.

Freud, S. (1949). Three essays on the theory of sexuality. Oxford England: Imago Publ. Co..

Fuentes, M. D. M. S., \& Iglesias, P. S. (2014). A systematic review of sexual satisfaction. International Journal of Clinical and Health Psychology, 14(1), 67-75.

Fyfe, B. (1980). Counseling and human sexuality: A training model. The Personnel and Guidance Journal, 59(3), 147-150.

Giami, A. (2002). Sexual health: The emergence, development, and diversity of a concept. Annual Review of Sex Research, 13(1), 1-35.

Giami, A. (2015). Between DSM and ICD: Paraphilias and the transformation of sexual norms. Archives of Sexual Behavior, On-line First. Retrieved from http://ink.springer.com/article/10.1007/s10508-015-0549-6. Accessed 5 May 2015.

Gray, L. A., Cummins, E. J., Johnson, B. P., \& Mason, M. J. (1989). Human sexuality instruction in counselor education curricula. Counselor Education and Supervision, 28(4), 305-317. https://doi.org/10.1002/j.15566978.1989.tb01121.x.

Gray, L. A., House, R. M., \& Eicken, S. (1996). Human sexuality instruction: Implications for couple and family counselor educators. The Family Journal, 4(3), 208-216.

Haboubi, N. H. J., \& Lincoln, N. (2003). Views of health professionals on discussing sexual issues with patients. Disability \& Rehabilitation, 25(6), 291-296.

Hanzlik, M., \& Gaubatz, M. (2012). Clinical PsyD trainees' comfort discussing sexual issues with clients. American Journal of Sexuality Education, 7(3), 219-236. https://doi.org/10.1080/15546128.2012.707080.

Harris, S. M., \& Hays, K. W. (2008). Family therapist comfort with and willingness to discuss client sexuality. Journal of Marital and Family Therapy, 34(2), 239-250.

Heiman, J. R. (2002). Sexual dysfunction: Overview of prevalence, etiological factors, and treatments. Journal of Sex Research, 39(1), 73-78.

Hertlein, K. M., Weeks, G. R., \& Gambescia, N. (2012). A clinician's guide to systemic sex therapy. New York: Routledge.

Higgins, A., Barker, P., \& Begley, C. M. (2006). Sexuality: The challenge to espoused holistic care. International Journal of Nursing Practice, 12(6), 345-351.

Juergens, M. H., Smedema, S. M., \& Berven, N. L. (2009). Willingness of graduate students in rehabilitation counseling to discuss sexuality with clients. Rehabilitation Counseling Bulletin, 53(1), $34-43$.

Kaplan, H. S. (1974). The new sex therapy. New York: Brunner/Mazel, Inc..

Kelly, G. F. (1976). Sex education for counselors. The Personnel and Guidance Journal, 54(7), 354-357.

Kolmes, K., Stock, W., \& Moser, C. (2006). Investigating bias in psychotherapy with BDSM clients. Journal of Homosexuality, 50(2-3), 301-324.

Kooyman, L. E. (2008). Predictors of high-risk sexual behavior among gay men and men who have sex with men. Journal of LGBT Issues in Counseling, 2(4), 285-307.

Leiblum, S. R. (2006). Sex therapy today: Current issues and future perspectives. In S. R. Leiblum (Ed.), Principles and practice of sex therapy (pp. 3-24). New York: Guilford Press.

Lewis, A. (2012). Just your average joe: Getting to know a lifestyle kinkster. Counselling Australia, 12(2), 1-8.

Lydon, J., \& Karremans, J. C. (2015). Relationship regulation in the face of eye candy: A motivated cognition framework for understanding responses to attractive alternatives. Current Opinion in Psychology, 1, 76-80.

Martinson, F. M. (1994). The sexual life of children. Westport: Greenwood Publishing Group.

Masters, W. H., \& Johnson, V. E. (1966). Human sexual response. Oxford England: Little, Brown.

Masters, W. H., \& Johnson, V. E. (1970). Human sexual inadequacy. Boston: Little, Brown, and Company. 
Masters, W. H., Johnson, V. E., Kolodny, R. C., \& Bergen, M. B. (1995). Human sexuality. New York: HarperCollins College Publishers.

McCabe, M., Althof, S. E., Assalian, P., Chevret-Measson, M., Leiblum, S. R., Simonelli, C., \& Wylie, K. (2010). Psychological and interpersonal dimensions of sexual function and dysfunction. The journal of Sexual Medicine, 7(1pt2), 327-336.

McCabe, M. P., \& Taleporos, G. (2003). Sexual esteem, sexual satisfaction, and sexual behavior among people with physical disability. Archives of Sexual Behavior, 32(4), 359-369.

Meyer-Bahlburg, H. F. (2005). Introduction: Gender dysphoria and gender change in persons with intersexuality. Archives of Sexual Behavior, 34(4), 371-373.

National Board for Certified Counselors. (2012). Code of ethics. Greensboro: Author.

Pfaus, J. G., Kippin, T. E., \& Centeno, S. (2001). Conditioning and sexual behavior: A review. Hormones and Behavior, 40(2), 291-321.

Pleck, J. H. (1995). The gender role strain paradigm: An update. In R. F. Levant \& W. S. Pollack (Eds.), A new psychology of men (pp. 11-32). New York: Basic Books.

Price, J. (2011). Naked at our age: Talking out loud about senior sex. Berkeley: Seal Press.

Ravitz, P., Maunder, R., Hunter, J., Sthankiya, B., \& Lancee, W. (2010). Adult attachment measures: A 25 -year review. Journal of Psychosomatic Research, 69(4), 419-432.

Rosser, B. S., Dwyer, S. M., Coleman, E., Miner, M., Metz, M., Robinson, B. E., \& Bockting, W. O. (1995). Using sexually explicit material in adult sex education: An eighteen year comparative analysis. Journal of Sex Education and Therapy, 21(2), 117-128.

Russell, E. B. (2012). Sexual health attitudes, knowledge, and clinical behaviors implications for counseling. The Family Journal, 20(1), 94-101.

Samenow, C. P. (2012). Why human subject research protection is important in sex addiction. Sexual Addiction \& Compulsivity, 19(3), 161-167.

Schur, E. M. (1988). The Americanization of sex. Philadelphia: Temple University Press.

Sherry, A., \& Amidon, A. (2010). The ethics of sex research on the internet. In D. L. Streiner, S. Sidani, D. L. Streiner, \& S. Sidani (Eds.), When research goes off the rails: Why it happens and what you can do about it (pp. 27-33). New York: Guilford Press.

Shively, M. G., \& de Cecco, J. P. (1993). Components of sexual identity. In L. D. Garnets \& D. C. Kimmel (Eds.), Psychological perspectives on lesbian and gay male experiences (pp. 80-88). New York: Columbia University Press.

Simons, J. S., \& Carey, M. P. (2001). Prevalence of sexual dysfunctions: Results from a decade of research. Archives of Sexual Behavior, 30(2), 177-219.

Sitron, J. A., \& Dyson, D. A. (2009). Sexuality attitudes reassessment (SAR): Historical and new considerations for measuring its effectiveness. American Journal of Sexuality Education, 4(2), 158-177.

Sitron, J. A., \& Dyson, D. A. (2012). Validation of sexological worldview: A construct for use in the training of sexologists in sexual diversity. SAGE Open, 2(1), 2158244012439072.

Southern, S., \& Cade, R. (2011). Sexuality counseling: A professional specialization comes of age. The Family Journal. https://doi.org/10.1177/1066480711408028.

Stayton, W. R. (1998). A curriculum for training professionals in human sexuality using the sexual attitude restructuring (SAR) model. Journal of Sex Education and Therapy, 23(1), 26-32.

Stefanou, C., \& McCabe, M. P. (2012). Adult attachment and sexual functioning: A review of past research. The Journal of Sexual Medicine, 9(10), 2499-2507.

Stoyanova, S. (2011). Emotional intelligence and personality constructs. Romanian Journal of School Psychology, 4(8), 57-75.

Teyber, E., \& McClure, F. H. (2011). Interpersonal process theory: An integrative approach. Cengage Learning: Belmont.

Timm, T. M. (2009). "Do I really have to talk about sex?” encouraging beginning therapists to integrate sexuality into couples therapy. Journal of Couple \& Relationship Therapy, 8(1), 15-33.

Timm, T. M., \& Keiley, M. K. (2011). The effects of differentiation of self, adult attachment, and sexual communication on sexual and marital satisfaction: A path analysis. Journal of Sex \& Marital Therapy, 37(3), 206-223.

Van Sevenant, A. (2005). Sexual outercourse: Philosophy of lovemaking. Leuven Belgium: Peeters Publishing.

Weaver, H., Smith, G., \& Kippax, S. (2005). School-based sex education policies and indicators of sexual health among young people: A comparison of the Netherlands, France, Australia and the United States. Sex Education, 5(2), 171-188.

Weeks, J. (2002). Sexuality and its discontents: Meanings, myths, and modern sexualities. New York: Routledge. Wiederman, M. W. (1998). The state of theory in sex therapy. Journal of Sex Research, 35(1), 88-99.

Wilcox, A. J., Dunson, D., \& Baird, D. D. (2000). The timing of the "fertile window" in the menstrual cycle: Day specific estimates from a prospective study. British Medical Journal, 321(7271), 1259-1262. 
World Health Organization. (2006). Defining sexual health. Geneva: Author.

Young, L. (2015, February 24). Sexual education compared across Canada. Retrieved from http://globalnews. ca/news/1847912/sexual-education-compared-across-canada/. Accessed 8 May 2017.

Zeglin, R. J. (2014). Participation in prostitution: Associated outcomes within familial relationships. Sexuality Research and. Social Policy, 11(1), 50-62.

Zeglin, R. J. (2015). Assessing the role of masculinity in the transmission of HIV: A systematic review to inform HIV risk reduction counseling interventions for men who have sex with men. Archives of Sexual Behavior, 44(7), 1979-1990.

Zeglin, R. J., \& Mitchell, J. (2014). Using social media to assess conceptualizations of sexuality. American Journal of Sexuality Education, 9(3), 276-291. 